\title{
Prevalence of Oral Cancer in Patients Reporting to Private Dental Hospital
}

\section{IJCRR}

Section: Healthcare

Sci. Journal Impact

Factor: 6.1 (2018)

ICV: 90.90 (2018)

(c) (i) (8)

Copyright@IJCRR

\section{Neha Sharma $\mathbf{M}^{1}$, Senthil Murugan $\mathbf{P}^{2}$, L Leelavathi ${ }^{3}$}

'Saveetha Dental College \& Hospitals, Saveetha Institute of Medical and Technical Sciences, Saveetha University, Chennai- 60oo77, India; ${ }^{2}$ Associate Professor, Department of Oral and Maxillofacial Surgery, Saveetha Dental College \& Hospitals, Saveetha Institute of Medical and Technical Science, Saveetha University, Chennai-60oo77, India; 3 Senior Lecturer, Department of Public Health Dentistry, Saveetha Dental College \& Hospitals, Saveetha Institute of Medical and Technical Sciences, Saveetha University, Chennai-600077, India.

\section{ABSTRACT}

Background: Oral cancer is one of the 10 most common cancers in the world, with delayed clinical detection, poor prognosis, for the disease, and expensive therapeutic alternatives. Oral cancer is a preventable disease, risk factors and natural history is already being known, where biomedical sciences and dentistry, in particular, are likely to improve their poor clinical indicators.

Objevtive: The aim of this study is to assess the prevalence of oral cancer among patients visiting Saveetha Dental College.

Methods: A retrospective study was carried out and the case records of patients having oral cancer were collected by reviewing patient records and analyzing the data of 86000 patients from June 2019 to April 2020. Patients diagnosed with oral cancer were selected. The data were collected and subjected to statistical analysis and correlation using SPSS software.

Results: In this study, it was found that $82 \%$ of the total patients diagnosed with oral cancer were males and $18 \%$ of them were females. It was also found that the commonest site involved was the buccal mucosa (31\%). The findings of this study revealed that oral cancer is more prevalent among males and that the commonest site involved is the buccal mucosa.

Conclusion: From this study it is concluded that the prevalence of oral cancer is more among males and according to the site involved, it's more commonly involved in buccal mucosa when compared to other sites.

Key Words: Buccal mucosa, Correlation, Diagnosis, Gender, Oral cancer, Subsite

\section{INTRODUCTION}

Oral cancer is a highly relevant problem of global public health, especially for dental surgeons. Oral cancer is malignant neoplasia that arises in the oral cavity and is traditionally defined as a squamous cell carcinoma (OSCC) because in the dental area, $90 \%$ of cancers are histologically originated in the squamous cells. ${ }^{1}$ The most common etiological factors associated with oral cancer are tobacco accompanied by excessive alcohol use, as well as Human Papillomavirus (HPV) infection ${ }^{2}$; HPV being mostly associated with oropharyngeal subset. $^{3}$ Globally, there are geographical variations in oral cancer incidence. The highest rate is reported in Melanesia of the Pacific region, with incidence rates of $22.9 \%$ in 100,000 men and $16 \%$ per 100,000 for women. ${ }^{4}$ Some countries with the highest incidence rates for oral cancer in the world are located in the region of South Asia. ${ }^{5}$ India has been recognized as the country with the highest incidence of oral cancer in the world, though in some recent reports Sri Lanka and Paki- stan are ranked in the top. ${ }^{6}$ Oral and pharyngeal carcinomas comprise up to half of all malignancies in India and other Asian countries, with high prevalence being attributed to the influence of carcinogens and region-specific epidemiological factors, especially tobacco and betel quid chewing. ${ }^{7}$ The incidence and mortality rates of oral cancer are particularly higher among men than women. ${ }^{8}$ Most malignant tumors of the oral cavity are squamous cell carcinomas, followed by adenocarcinomas and rarely other types of malignant tumors ${ }^{9}$. Although it is well known that most oral cancer patients are from older age groups, there is a recent trend of the rising incidence of oral cancer in younger patients, particularly on the tongue. ${ }^{10}$ Although drinking and smoking are independent risk factors, they have a synergistic effect and greatly increase risk together. ${ }^{11}$

In some parts of India, such as the states of Bihar and Maharashtra, smokeless tobacco use is more common than smoking. Apart from regional preferences due to differing

\section{Corresponding Author:}

Dr. Senthil Murugan P, Associate Professor, Department of Oral and Maxillofacial Surgery, Saveetha Dental College \& Hospitals, Saveetha Institute of Medical and Technical Science, Saveetha University, Chennai-600077, India; Ph:+91-9790869469; E-mail: senthilmuruganp.sdc@saveetha.com

ISSN: 2231-2196 (Print)

Received: 12.08 .2020
ISSN: 0975-5241 (Online)

Revised: 07.09 .2020
Accepted: 10.10 .2020 
socio-cultural norms, the preference for smokeless tobacco is inversely related to education and income. ${ }^{12}$ Quitting tobacco smoking has been reported to reduce the risk of head and neck cancer in previous studies. ${ }^{13}$ Oral cancer is considered to be a preventable disease that is amenable to early detection and treatment. ${ }^{14}$ A conventional oral examination (COE), using normal (incandescent) light, has long been the standard method for oral cancer screening ${ }^{15}$. A careful history taking helps to generate a complete differential diagnosis and all diagnostic possibilities are considered prior to establishment of a definitive diagnosis. ${ }^{16}$

Implementation of effective, integrated, and multisectoral preventive strategies targeting multiple risk factors for cancer will reduce in the long-term the incidence of cancer in sites such as oral cavity. ${ }^{17}$ Hence, the aim of this study is to assess the prevalence of oral cancer among patients visiting Saveetha Dental College.

\section{MATERIALS AND METHODS}

\section{Study Design}

This is a retrospective study regarding patients diagnosed with oral cancer who have visited Saveetha Dental College and Hospitals between June 2019- April 2020. The case records of patients with oral cancer were collected by reviewing patient records and analyzing the data of 86000 patients. The final sample size of 51 patients in which sampling bias was minimized with the verification of photos and crossverification. The study was reviewed by two reviewers and it was cross verified. Ethical committee approval was obtained from the Institutional Ethics Committee (approval number: SDC/SIHEC/2020/DIASDATA/0619-0320).

Inclusion criteria - The patients diagnosed with oral cancer.

Exclusion criteria - An incomplete record in the system.

\section{Data Collection}

The data of these patients were collected and tabulated. It included parameters - Patients ID, Age, Gender, jaw involved, and subsite. Age was categorized into 30-40 years, 41-55 years, and patients more than 55 years. Jaws involved were upper, lower, and both arches. After further verification by an external reviewer, it was imported to SPSS software by IBM for statistical analysis. A similar methodology is used for other studies..$^{18-20}$

\section{Statistical analysis}

Percentage, mean, standard deviation, frequency of parameters were employed in the analysis. Chi-square test was used to detect the significance between age, gender, jaw involved and subsite. P-value of less than 0.05 was considered as statistically significant.

\section{RESULTS AND DISCUSSION}

In this study, a total of 51 patients were screened. Out of them, about $82 \%$ were males and only $18 \%$ were females [Figure 1]. Almost 50\% of the patients belonged to the $41-55$ years age group, whereas $42 \%$ of them were more than 55 years and 7\% were between $30-40$ years [Figure 2]. A maximum number of patients $(50 \%)$ presented with oral cancer in both arches whereas $44 \%$ in the lower arch and only $4 \%$ in the upper arch [Figure 3]. $31.1 \%$ of the patients were diagnosed with oral cancer involving buccal mucosa, $9 \%$ involving retromolar trigone, $3 \%$ in the posterior $1 / 3^{\text {rd }}$, and lateral border of the tongue [Figure 4].

On performing the Chi-square test, the correlation between age, jaw involved, and subsite revealed no significant correlation ( $p>0.05$ ) [Figure 5 and 6]; between gender, jaw involved and subsite showed similar results with no significant correlation ( $p$-value $>0.05$ ) [Figure 7 and Table 1]. Correlation between subsite and jaws involved in oral cancer revealed that among the patients with cancer involving both arches, buccal mucosa was the most involved site, although it showed no significance $(\mathrm{p}>0.05)$ [Table 2].

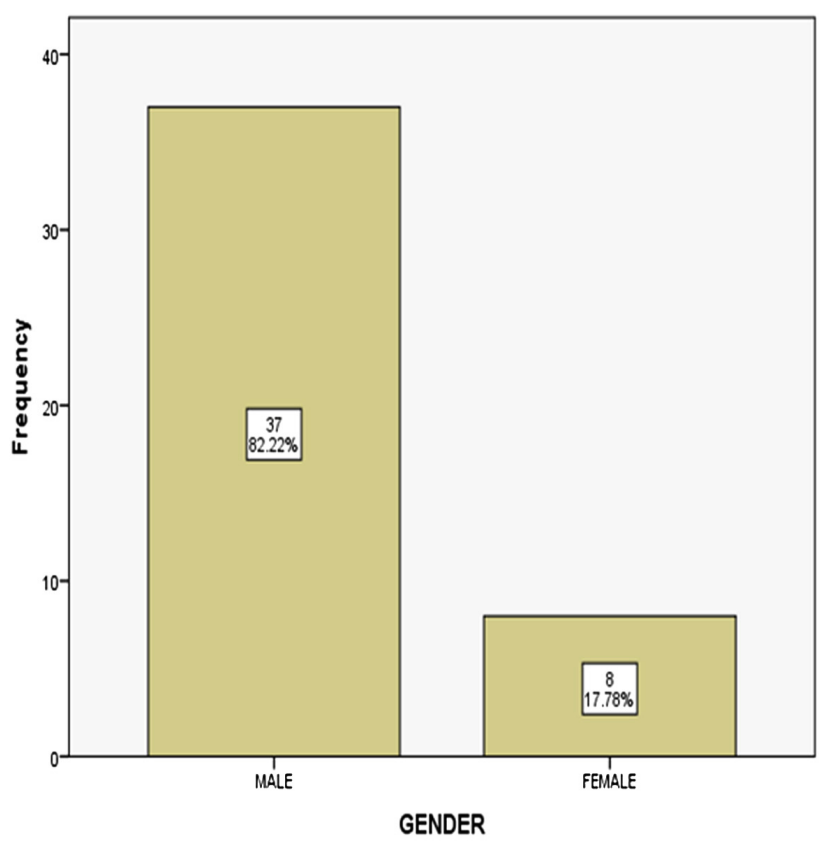

Figure 1: Bar graph depicting the prevalence of oral cancer among different gender of patients visiting the dental college. $Y$-axis represents the frequency of oral cancer patients over a year and $\mathrm{X}$-axis represents the gender of the patients. The graph shows that $82.2 \%$ of the patients having oral cancer were males and $17.7 \%$ were females. This study showed that oral cancer was more prevalent among males. 


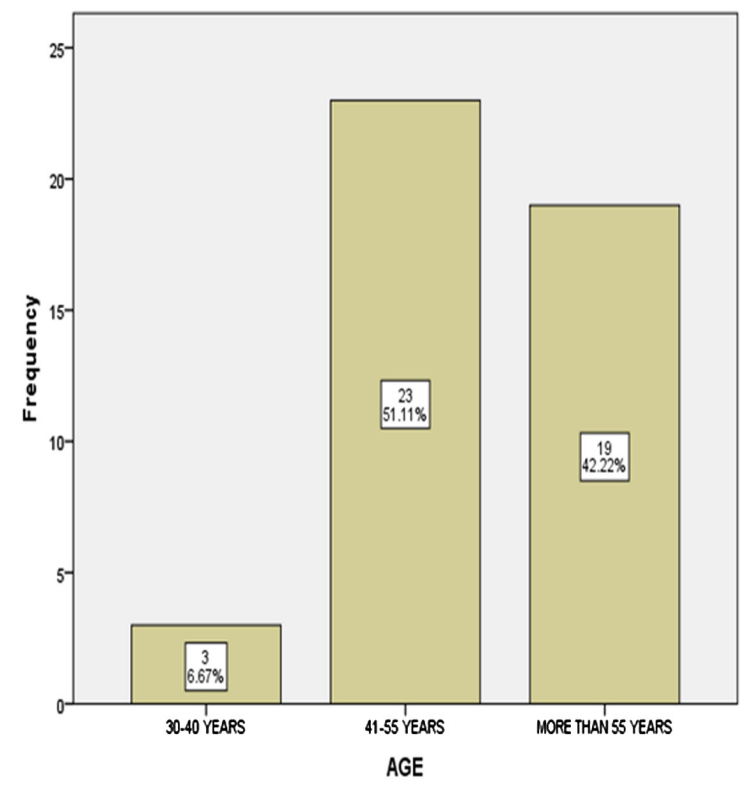

Figure 2: Bar graph depicting the prevalence of oral cancer among different age groups of patients visiting the dental college. Y-axis represents the frequency of oral cancer patients over a year and $\mathrm{X}$-axis represents the age of the patients. The graph shows that $51.1 \%$ of the patients having oral cancer were between $41-55$ years, $42.2 \%$ of the patients were more than 55 years old and $6.6 \%$ of the patients were $30-40$ years. In this study, we observed that the incidence of oral cancer is high in patients with 41-55 yrs age group.

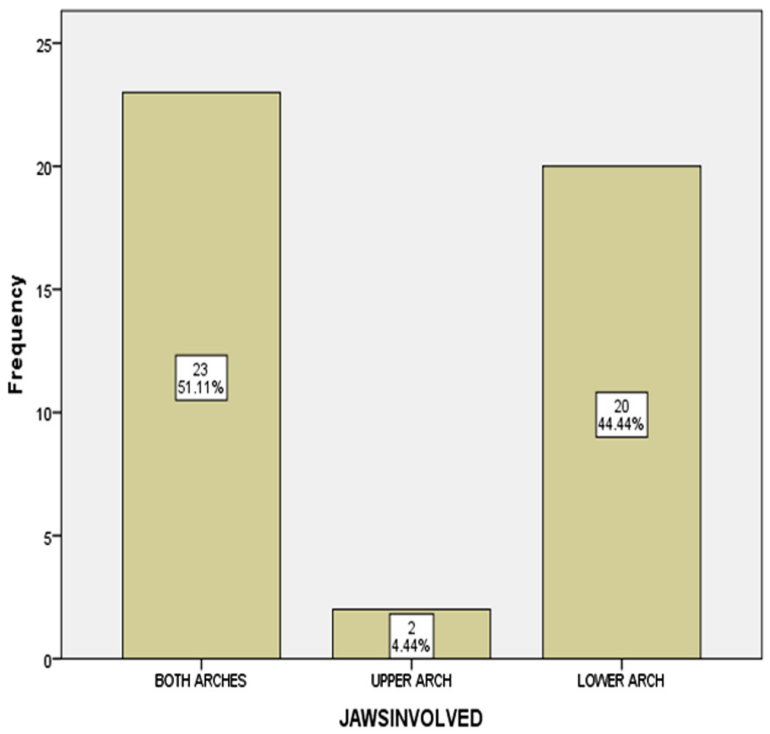

Figure 3: Bar graph depicting the jaws involved in oral cancer among patients visiting the dental college. Y-axis represents the frequency of oral cancer patients over a year and $X$-axis represents the jaws involved in oral cancer. The graph shows that $51.1 \%$ of the patients had oral cancer involving both arches, $44.4 \%$ of the patients had in the lower arch and $4.4 \%$ of the patients had oral cancer involving the upper arch. In this study, we observed that both arches were commonly involved in oral cancer.

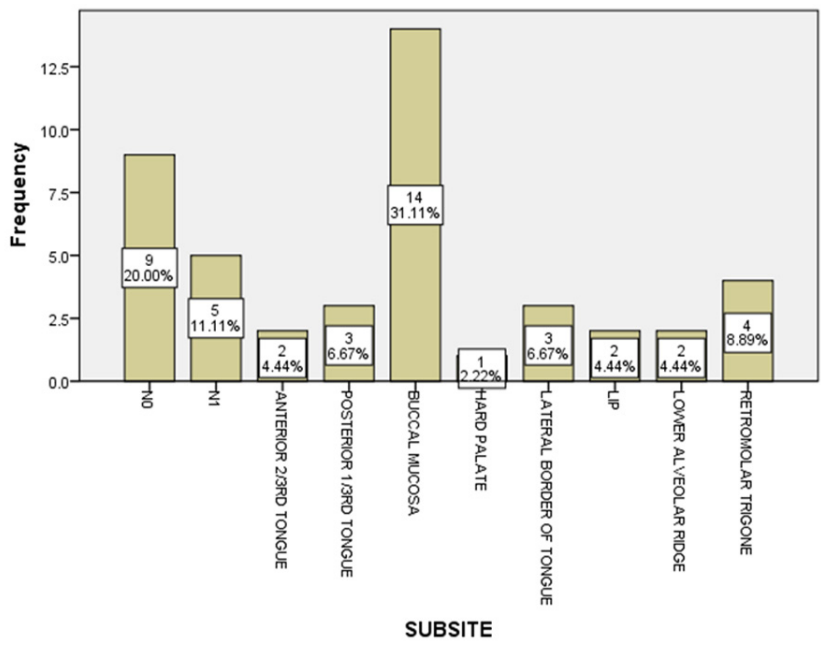

Figure 4: Bar graph depicting the subsite of oral cancer among patients visiting the dental college. Y-axis represents the frequency of oral cancer patients over a year and $\mathrm{X}$-axis represents the subsite of oral cancer. The graph shows that $31.1 \%$ of the patients had oral cancer in the buccal mucosa, $8.9 \%$ of them had oral cancer in the retromolar trigone and $6.6 \%$ of them had in posterior $1 / 3^{\text {rd }}$ of the tongue. This study revealed that the incidence of oral cancer is more in buccal mucosa and the least involved site is the hard palate

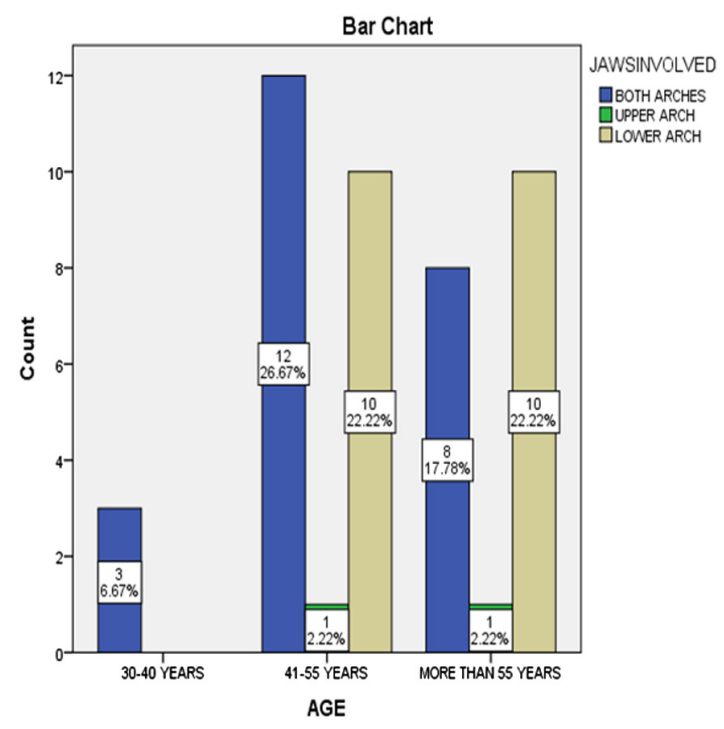

Figure 5: Bar graph depicting the correlation between age and jaws involved in oral cancer. Y-axis represents the jaws involved in oral cancer and $\mathrm{X}$-axis represents the age of the patients. The color blue denotes both arches, green color denotes the upper arch and brown color denotes the lower arch. From the graph, we found that among the patients in the age group 41-55 years, both arches were most commonly involved, and in patients more than 55 years old, the lower arch was more prevalent. But there was no significant association between age and the jaw involved in oral cancer. Chi-square value is $p-0.478$ ( $p>0.05$ not statistically significant). 


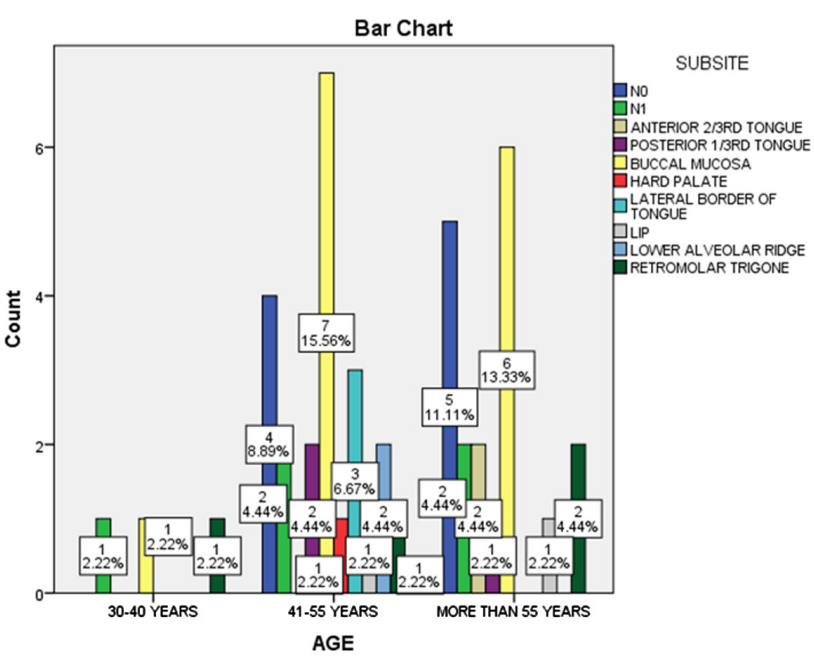

Figure 6: Bar graph depicting the correlation between age and subsite involved in oral cancer among the patients visiting a private dental hospital. Y-axis represents the subsite in oral cancer and $\mathrm{X}$-axis represents the age of the patients. From the graph, it was evident that among patients between 41-55 years and those more than 55 years, buccal mucosa was the commonest site whereas, in patients between 30-40 years, retromolar trigone along with buccal mucosa was the commonest site involved. But there was no significant association between age and the subsite in oral cancer. Chi-square value is $p-0.718$ ( $p>0.05$ not statistically significant).

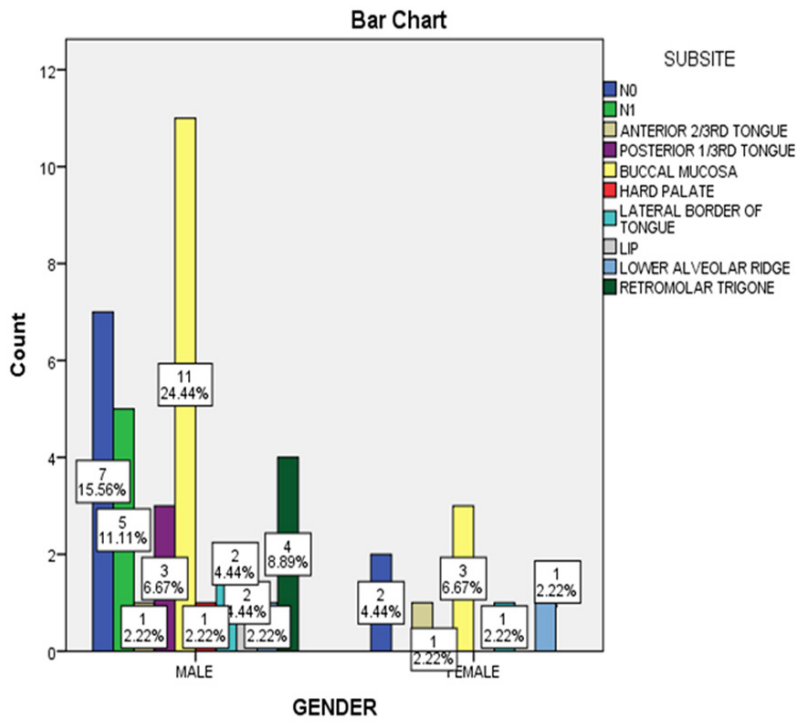

Figure 7: Bar graph depicting the correlation between gender and subsite involved in oral cancer among patients visiting a private dental hospital. Y-axis represents the subsite in oral cancer and $\mathrm{X}$-axis represents the gender of the patients. From the study, we found that among both males and females, buccal mucosa was more commonly involved when compared to other sites followed by retromolar trigone and posterior $1 / 3^{\text {rd }}$ of the tongue. But there was no significant association between gender and the subsite involved in oral cancer. Chi-square value $p-0.655$ [ $p>0.05$ not statistically significant).
Table 1: Table depicting the correlation between gender and jaw involved. From the table, it was evident that there was no significant correlation between gender and the jaw involved in oral cancer. Chisquare value $p-0.466[p>0.05)$.

\begin{tabular}{lccc} 
Tests & Value & df & $\begin{array}{c}\text { Asymptotic Significance } \\
\text { (2-sided) }\end{array}$ \\
\hline Pearson Chi-Square & $1.529^{\mathrm{a}}$ & 2 & 0.466 \\
Likelihood Ratio & 1.186 & 2 & 0.553 \\
Linear-by-Linear & .034 & 1 & 0.854 \\
Association & & & \\
N of Valid Cases & 45 & & \\
\hline
\end{tabular}

Table 2: Table depicting the correlation between subsite and jaw involved in oral cancer. From the table, it was evident that there was no significant correlation between the subsite and the jaw involved. Chi-square value $0.291[p>0.05)$

\begin{tabular}{lccc} 
Tests & Value & df & $\begin{array}{c}\text { Asymptotic Sig- } \\
\text { nificance (2-sided) }\end{array}$ \\
Pearson Chi-Square & $20.779^{\mathrm{a}}$ & 18 & .291 \\
Likelihood Ratio & 17.737 & 18 & .473 \\
$\begin{array}{l}\text { Linear-by-Linear As- } \\
\text { sociation }\end{array}$ & .240 & 1 & .624 \\
N of Valid Cases & 45 & & \\
\hline
\end{tabular}

Worldwide there are 350,000-400,000 new cases of oral cancer diagnosed each year. Unlike most other anatomic sites, which have decreased in cancer incidence, the incidence of oral cancer is increasing, particularly among young people and women. ${ }^{21}$

Development of oral or head and neck squamous cell carcinoma (HNSCC) and minor salivary gland carcinomas is influenced by factors namely tobacco, alcohol, viruses, diet and nutrition, radiation, oral thrush, immunosuppression, use of mouthwash, syphilis, dental factors, ethnicity, familial and genetic predisposition, and occupational risks. ${ }^{22}$ Although information around tobacco exposure as a presiding risk factor for oral and other cancers is now more prevalent, the relationship between alcohol consumption and oral cancer remains uncredited ${ }^{23}$. Oral cancer poses significant mortality and morbidity in the patients, especially when discovered late in the course of the disease. ${ }^{24}$ Oral squamous cell carcinoma (OSCC) is the most frequent oral malignancy. ${ }^{25}$ Oral cancer has one of the lowest five-year survival rates among the major types of cancers, including breast, skin, testis, prostate, uterus, and urinary bladder cancers with survival rates of $50 \%$ or less. ${ }^{26}$ The difference in incidence and pattern of oral carcinoma can be attributed to an overall effect of aging of the population as well as some regional differences in the prevalence of certain etiological factors. ${ }^{27}$ Some of the 
recognized risk factors are: tobacco in various forms - smoking as well as smokeless/chewing tobacco; areca nut; heavy consumption of alcohol; infection with human papillomavirus; and presence of oral potentially malignant disorders, all of the above frequently having their effects in a background of diets deficient in antioxidant vitamins and minerals. ${ }^{28}$ Consumption of areca nut causes other conditions like oral submucous fibrosis. ${ }^{29}$ Typical signs and symptoms of oral cancer includes white and red patches on the lining of the oral mucosa, ${ }^{30}$, unhealed oral ulcers, swellings of the mouth, loosening of one or more teeth without obvious reason ${ }^{31}$, jaw pain and stiffness, difficulty or pain in swallowing ${ }^{32}$, speech difficulties, reduced mobility of the tongue, numbness of the tongue or teeth or lips, bleeding of unknown origin, neck swelling, fetor oris, altered dental occlusion, sore throat, painful tongue and hoarse voice..$^{33}$ It is important for dental students to improve their knowledge to enable diagnosis and management of oral cancer and conditions like HIV/AIDS. ${ }^{34}$

In our study, $82 \%$ of the patients were males and $18 \%$ of the patients were females. This is supported by a study that shows that $80 \%$ of the cases were seen in males whereas only $20 \%$ of the cases were seen in females with a male to female ratio of $4: 1 .^{35} \mathrm{~A}$ high male predominance was noted in patients with cancer of buccal mucosa. According to the findings of this study, most of the patients (31\%) had cancer of buccal mucosa. Previous literature revealed that $40.8 \%$ of malignancies occurred on the buccal mucosa, $25.6 \%$ on the tongue and $5.2 \%$ on the lower lip ${ }^{36}$ whereas another study was done in Thailand revealed that the tongue and palate were the most common site involved. ${ }^{37}$ Another study showing similar findings revealed that tongue was the commonest site identified in $52 \%$ of the patients followed by buccal mucosa in $26 \%$ of the patients. ${ }^{38}$ Our study revealed that $51 \%$ of the patients were $41-55$ years old, $42 \%$ of them were more than 55 years old and only $7 \%$ of the patients were $30-40$ years old. Similar results were shown by a study which indicated that $74 \%$ of the malignant cases are seen in the patients with 40-65 years old ${ }^{39}$ and majority of the patients (about $55 \%$ ) presented between the ages of $40-60$ years. ${ }^{40}$ Early examinations are more likely to result in early-stage diagnosis, which in turn is linked to reduced mortality and favorable treatment outcomes. The challenge facing health professionals is getting people, particularly people at high risk for oral cancer, to undergo an oral cancer examination..$^{41}$ Currently, tissue biopsy remains the gold standard for oral cancer diagnosis, but it is invasive, which may cause patient discomfort. Thus, there is an urgent need for exploring non-invasive, highly sensitive, and specific diagnostic techniques. ${ }^{42}$

Although our findings did not show any significant relevance, it helps to assess the occurrence of cancer among patients from different ethical and socioeconomic groups. Our study also helps to make Health care providers place greater emphasis on educating patients about the importance of vis- iting a clinician as soon as oral symptoms develop. Public education efforts must also continue to encourage patients to avoid high-risk behaviors as tobacco or alcohol use. Dental anxiety and fear are common among patients ${ }^{43}$ but dentists should serve as an aid during the screening of such malignant conditions and the main concern of the dentist for their patients is to minimize the experience of pain ${ }^{44}$ and patient's anxiety is undesirable side effect which affect the willingness of the patient to undergo treatment. ${ }^{45}$

\section{CONCLUSION}

It was found from our study that the prevalence of oral cancer was more among the males, who presented with oral cancer involving mostly the buccal mucosa. This study helps to evaluate awareness, knowledge of risk factors, identifying early signs, symptoms of oral cancer, and highlights the need for more structured preventive programs. Histomorphological and molecular parameters at this biological hot spot of tumor-host interface seem to be potential tools to be incorporated into a prognostic system that will better reflect the biologic diversity of oral cancer and more accurately predict clinical outcome and/or response to a particular type of adjuvant therapy. Dentists and health workers should give more emphasis on this by performing oral cancer screening, raising levels of knowledge, and rectifying misconceptions about oral cancer.

\section{ACKNOWLEDGEMENT}

The authors are grateful to Saveetha Dental College for providing a platform to express our knowledge.

\section{Conflict of Interest}

No potential conflict of interest relevant to this article was reported

\section{Funding Information}

No funding involved

\section{REFERENCES}

1. Rivera C. Essentials of oral cancer. Int J Clin Exp Pathol 2015; 8: 11884-11894.

2. Jain SV, Vijayakumar Jain S, Muthusekhar MR, Senthilnathan P, Loganathan S, Wahab PUA, et al. Evaluation of Three-Dimensional Changes in Pharyngeal Airway Following Isolated Lefort One Osteotomy for the Correction of Vertical Maxillary Excess: A Prospective Study. J Maxillofac Oral Surg 2019; 18: 139-146.

3. Osazuwa-Peters N, Boakye EA, Hussaini AS, Sujijantara N, Ganesh RN, Snidder N, et al. Characteristics and predictors of oral cancer knowledge in a predominantly African American community. PLoS One 2017; 12: e0177787. 
4. Fu JY, Wu CX, Zhang CP, Gao J, Luo GF, Shen SK, et al. Oral cancer incidence in Shanghai - a temporal trend analysis from 2003 to 2012. BMC Cancer 2018;18(1):686.

5. Kumar S, Rahman R. Knowledge, Awareness, and Practices Regarding Biomedical Waste Management Among Undergraduate Dental Students. Asian J Pharma Clin Res 2017; 10: 341.

6. Warnakulasuriya S. Global epidemiology of oral and oropharyngeal cancer. Oral Oncology 2009; 45: 309-316.

7. Tanaka T, Ishigamori R. Understanding carcinogenesis for fighting oral cancer. J Oncol 2011; 2011: 603740.

8. Dissanayaka WL, Pitiyage G, Kumarasiri PVR, Liyanage RL, Dias KD, Tilakaratne WM. Clinical and histopathologic parameters in survival of oral squamous cell carcinoma. Oral Surg Oral Med Oral Pathol Oral Radiol 2012; 113: 518-525.

9. Bettendorf O, Piffkò J, Bànkfalvi A. Prognostic and predictive factors in oral squamous cell cancer: important tools for planning individual therapy? Oral Oncology 2004; 40: 110-119.

10. Siriwardena BSMS, Tilakaratne A, Amaratunga EAPD, Tilakaratne WM. Demographic, aetiological and survival differences of oral squamous cell carcinoma in the young and the old in Sri Lanka. Oral Oncology 2006; 42: 831-836.

11. Tsantoulis PK, Kastrinakis NG, Tourvas AD. Advances in the biology of oral cancer. Oral Oncology 2007; 43: 523-534.

12. Gupta PC, Ray CS. Smokeless tobacco and health in India and South Asia. Respirology 2003; 8: 419-431.

13. Marron M, Boffetta P, Zhang ZF. Cessation of alcohol drinking, tobacco smoking and the reversal of head and neck cancer risk. Int J Epidemiol 2010; 39: 182-196.

14. Patturaja K, Pradeep D. Awareness of Basic Dental Procedure among General Population. Res J Pharma Tech 2016; 9: 1349.

15. Lingen MW, Kalmar JR, Karrison T. Critical evaluation of diagnostic aids for the detection of oral cancer. Oral Oncology 2008; 44: $10-22$.

16. Mangalath U, Mikacha MK, Khadar AHA, et al. Recent trends in prevention of oral cancer. J Int Soc Prev Comm Dentis 2014; 4: 131 .

17. Petersen PE. Oral cancer prevention and control - The approach of the World Health Organization. Oral Oncology 2009; 45: 454-460.

18. Jesudasan JS, Abdul Wahab PU, Muthu Sekhar MR. Effectiveness of $0.2 \%$ chlorhexidine gel and a eugenol-based paste on postoperative alveolar osteitis in patients having third molars extracted: a randomised controlled clinical trial. Br J Oral Maxillofac Surg 2015; 53: 826-830.

19. Abhinav R, Selvarasu K, Maheswari G, et al. The patterns and etiology of maxillofacial trauma in South India. Ann Maxillofac Surg 2019; 9: 114.

20. Kumar S, Sneha S. Knowledge and Awareness Regarding Antibiotic Prophylaxis for Infective Endocarditis Among Undergraduate Dental Students. Asian J Pharma Clin Res 2016; 154.

21. Schmidt BL, Kuczynski J, Bhattacharya A, et al. Changes in Abundance of Oral Microbiota Associated with Oral Cancer. PLoS ONE 2014; 9: e98741.

22. Kumar M, Nanavati R, Modi T, et al. Oral cancer: Etiology and risk factors: A review. Journal of Cancer Research and Therapeutics 2016; 12: 458.

23. Shimpi N, Jethwani M, Bharatkumar A, et al. Patient awareness/ knowledge towards oral cancer: a cross-sectional survey. BMC Oral Health 2018; 18: 86.

24. Dhanuthai K, Rojanawatsirivej S, Thosaporn W, et al. Oral cancer: A multicenter study. Medicina Oral Patología Oral y Cirugia Bucal 2017; 0-0.

25. Marimuthu M, Andiappan M, Wahab A, et al. Canonical Wnt pathway gene expression and their clinical correlation in oral squamous cell carcinoma. Indian J Dent Res 2018; 29: 291-297.

26. Pisani P, Maxwell Parkin D, Bray F, et al. Estimates of the worldwide mortality from 25 cancers in 1990. Int J Cancer 1999; 83: 18-29.

27. Sharma S, Satyanarayana L, Asthana S, et al. Oral cancer statistics in India on the basis of first report of 29 population-based cancer registries. J Oral Maxillofac Pathol 2018; 22: 18-26.

28. Gupta B, Johnson NW. Systematic review and meta-analysis of association of smokeless tobacco and of betel quid without tobacco with incidence of oral cancer in South Asia and the Pacific. PLoS One 2014; 9: e113385.

29. Patil SB, Durairaj D, Suresh Kumar G, et al. Comparison of Extended Nasolabial Flap Versus Buccal Fat Pad Graft in the Surgical Management of Oral Submucous Fibrosis: A Prospective Pilot Study. J Maxillofac Oral Surg 2017; 16: 312-321.

30. Christabel A, Anantanarayanan P, Subash P, et al. Comparison of pterygomaxillary dysjunction with tuberosity separation in isolated Le Fort I osteotomies: a prospective, multi-centre, tripleblind, randomized controlled trial. Int J Oral Maxillofac Surg 2016; 45: 180-185.

31. Packiri S, Gurunathan D, Selvarasu K. Management of Paediatric Oral Ranula: A Systematic Review. J Clin Diagn Res 2017; 11: ZE06-ZE09.

32. Kumar S. The Emerging Role of Botulinum Toxin in the Treatment of Orofacial Disorders: Literature Update. Asian J Pharma Clin Res 2017; 10: 21.

33. Babiker TM, Osman KAA, Mohamed SA, et al. Oral Cancer Awareness Among Dental Patients in Omdurman, Sudan: a cross-sectional Study. BMC Oral Health 2017;17(1):69.

34. Kumar S. Knowledge, Attitude and Awareness of Dental Undergraduate Students Regarding Hiv/Aids Patients. Asian Journal of Pharmaceutical and Clinical Research 2017; 10: 175.

35. Suba Z. Gender-related hormonal risk factors for oral cancer. Pathology \& Oncology Research 2007; 13: 195-202.

36. Chen GS, Chen CH. A statistical analysis of oral squamous cell carcinoma]. Gaoxiong Yi Xue Ke Xue Za Zhi 1995; 11: $582-$ 588 .

37. Kerdpon D. Factors related to advanced stage oral squamous cell carcinoma in southern Thailand. Oral Oncology 2001; 37: 216-221.

38. Iype EM, Pandey M, Mathew A, et al. Oral cancer among patients under the age of 35 years. J Postgrad Med 2001; 47: 171176.

39. Jafari A, Najafi S, Moradi F, et al. Delay in the diagnosis and treatment of oral cancer. J Dent 2013; 14: 146-150.

40. Mishra A, Malik A, Garg A, et al. Trends of oral cancer with regard to age, gender, and subsite over 16 years at a tertiary cancer center in India. Indian J Med Paediatr Oncol 2018; 39: 297.

41. Shepperd JA, Emanuel AS, Howell JL, Logan HL. Predicting Scheduling and Attending for an Oral Cancer Examination. Ann Behav Med 2015; 49: 828-838.

42. Chen X-J, Zhang X-Q, Liu Q, Zhang J, Zhou G. Nanotechnology: a promising method for oral cancer detection and diagnosis. J Nanobiotechnology 2018;16(1):52.

43. Kumar S. Relationship Between Dental Anxiety and Pain Experience During Dental Extractions. Asian Pharma Clin Res 2017; 10: 458.

44. Rao TD, Santhosh Kumar MP. Analgesic Efficacy of Paracetamol Vs Ketorolac after Dental Extractions. Res J Pharma Tech 2018; 11: 3375.

45. Abhinav RP, Sweta VR, Ramesh A. Role of virtual reality in pain perception of patients following the administration of local anesthesia. Ann Maxillofac Surg 2019; 9: 110. 